\title{
Retention of Military Divers in The Royal Malaysian Navy Diving Organisation
}

\author{
Tay Yap Leong, Sharmila Jayasingam
}

Department of Business Policy \& Strategy, Faculty of Business and Accountancy, University Malaya, Malaysia.

\begin{abstract}
The RMN military divers are specifically trained to supplement the naval operation. They are capable to dive up to 60 meters, and perform specialized diving such as Mine Clearance Diving, Un-exploded Bomb Removal and Search and Rescue. According to the data from the year 2013 to 2018, the attrition rate of military divers is a major concern for the organisation. A total of 61 out of 100 divers retired early within this period. To make matters worse, retired divers were not replaced accordingly. Only 70 recruits joined this department, leaving the organization with a shortage of military divers. This study employed a Qualitative Descriptive Case Study to understand factors that influence early turnover and retention among the RMN military divers. The study suggests practical solutions and retention strategies to retain the current personnel so that they continue to serve until compulsory retirement. These solutions may also be beneficial in attracting new personnel. The research will use the Institutional Theory as the theoretical lens to explore the factors influencing military divers' intention to stay. The findings will be used to boost the retention rate of the military divers in the RMN.
\end{abstract}

$\underline{\text { Keywords: military diver, turnover, retention, institutional theory }}$

\section{INTRODUCTION}

Military divers are members of the Royal Malaysian Navy (RMN) who are assigned to diving missions. They have received specific training to assist in the naval operation. The RMN military divers provide the following services under National Defense Policy No.8: (1) diving up to 60 metres, (2) mine clearance diving, (3) unexploded bomb removal, and (4) search and rescue [1]. Even in times of peace, these divers continue to play an essential role by assisting government organisations such as the Malaysian Maritime Enforcement Agency, Fire and Rescue Department, and Marine Police in Search and Rescue diving [2].

The RMN's human resource (HR) statistical data from 2013 to 2018 reveals a military diver shortage. The number of military divers required has been set at 243 complements or roles. However, in 2019, the squad only had 171 military divers, resulting in a 72-person shortfall. Over the course of five years, from 2013 to 2018, RMN saw a 100-person turnover. Voluntary early retirement accounted for more than half $(61 \%)$ of the turnover among military divers with 12 to 15 years of service.

Unfortunately, the attrition and shortage of military divers are not supplemented adequately. Divers in the military are under-supplied. A total of 123 recruits enrolled in the military diving training in 2019. Only 70 of the recruits finished the course and stayed with the department. Furthermore, there is no guarantee that these 70 recruits will be able to finish the advanced training required to become proficient military divers, thereby alleviating the 72-person shortage. With the deployment of the RMN Literal Mission Ship and HQ East Command expansion programmes in 2013 and 2017, the shortfall is projected to grow. In conjunction with this development, a proposal for the inclusion of 49 complements has been submitted and is awaiting approval. The new requirement will unintentionally contribute to a 121-person military diver shortfall.

Fundamentally, the RMN's deficit has been exacerbated by a high attrition rate along with a poor passing rate for newly qualified competent military divers. The numbers show how serious the problem is. For many years, the RMN will be unable to meet the planned complement. Unfortunately, the unit's and the RMN's operations will be jeopardised by a dearth of skilled military divers to supplement the Diving Team. As a result, the goal of this study is to investigate and uncover the underlying causes of the RMN military divers' high attrition rate.

The study aims to address two research questions: (1) What are the factors that can influence the competent military divers to serve up to their compulsory retirement? (2) What are the suggested practical solutions to address attrition of competent military divers? As a result, the study's goals are twofold. The study's first goal is to determine the elements that can persuade skilled military divers to serve until they are forced to retire. Second, the study intends to offer practical ways for persuading qualified military divers to remain in the service.

Corresponding Author: Tay Yap Leong, Department of Business Policy \& Strategy, Faculty of Business and Accountancy, University Malaya, Malaysia. 
Tay \& Sharmila/ International Journal of Business and Management, 5 (2) 2021, Pages: 06-16

The findings of the study will aid the RMN Diving Organization in obtaining enough qualified military divers. This could be accomplished by identifying the elements that impact their desire to leave early and their readiness to serve until they are forced to retire. Insights into the important components would lay the groundwork for proposing a practical solution to the attrition problem.

\section{LITERATURE REVIEWS}

\subsection{Employee Retention}

According to Kaur (2017 p.162), employee retention is defined as 'A systematic effort by employers to create and foster an environment that encourages current employees to remain employed by having policies and practices in place that address their diverse needs'. Referring to Division (2019 p.1), military personnel retention is defined as 'The retention of qualified military personnel-enlisted forces and officers is essential to preserve morale and unit readiness and avoid the cost associated with training replacement personnel in essential skills' [3] [4].

The organization's management team should have a proper and workable policy in place to retain employees, or at the very least, reduce turnover. We must analyse an employee's retention through individual motivation and organisational elements in order to comprehend the effort of retaining employees in an organisation. Employee retention depends on what commitment level that an individual is ready to contribute. The employee will expect some form of compensation and rewards from the organisation because of their contributions and time spent. The individual will be looking for organisation support polices and acceptable human resource practises that create a great working environment so that the employee feels appreciated and stays with the company. Meeting the intrinsic and extrinsic needs of employees can help an organisation retain valuable employees [5] [6] [7] [8].

Employee retention, according to Hee and Rhung (2019), has various advantages. Employee retention has two advantages: cost savings and the retention of a skilled employee. By retaining current staff, the organisation can save down on hiring and training costs while also avoiding productivity losses. It will take time to train new personnel, and their productivity cannot be guaranteed. Aside from that, when individuals depart, the organization's critical knowledge, clients, current projects, and experience would be lost. As a result, every company will pay close attention to employee retention in order to reduce losses [9].

\subsection{Employee Turnover and Turnover Intention}

Employee turnover and turnover intention are terms used to describe the act of an employee quitting a company. According to Bankar, Kakade and More (2016 p.11), 'Employee turnover can be defined as an entry of new employees in an organisation and exit of the existing employee from an organisation'. Turnover Intention, on the other hand, is recorded when someone intends to quit an organisation and then decides to depart altogether after a period of time [10] [11]. Employee turnover can be classified into two types: voluntary and non-voluntary.

Aside from losing a bright and experienced team, the downsides of a high turnover rate would cost the organisation a fortune. The company will also have to restart the process of hiring new employees, which will result in increased training costs, a slowdown in output, and the loss of valuable expertise to a competitor if the employee joins the company.

\subsection{Employee Retention and Turnover Interrelation}

The connection between staff retention and turnover is apparent. Both terms allude to a company's ability to keep its human resources or employees [10] [11] [12] [13]. Retention focuses on preventing turnover and motivating people to stay on the job [14]. This is accomplished by addressing individual demands such as monetary pay, matching personal preferences such as desired workplace locations, and providing organisational support by looking after the welfare of employees, among other things. The ability to retain employees, particularly exceptional ones, will provide a competitive advantage for the company to prosper in any future expansion [3] [5] [15] [16] [17] [18].

To examine employee retention, the researcher must first comprehend the reasons that cause turnover. To investigate employee turnover, the researcher must look into the necessary reason to keep the employee. The interplay between the two keywords on retention and turnover will be the focus of this research on the retention of military divers in the RMN, based on the premise that these two concepts are intertwined. Various factors of employee turnover in an organisation have been discovered by researchers such as Kwon (2020), Lee (2018), Scott (2020), and Yang et al (2012). They identified factors that influence employee turnover and highlighted the impact of turnover on the organisation, particularly in terms of the loss of talented and competent employees as well as the increased costs of recruitment and training. Moving forward, these researchers advise that required retention tactics be implemented in order to lessen the detrimental impact of staff turnover [14]. Employee turnover or the intention to leave is linked to employee retention, according to these research [17] [19] [[20] [21]. 


\subsection{Theoretical Lens: Antecedents of Employee retention}

There are numerous studies on employee retention or employee turnover intention and the associated antecedents. A review of the literature indicate that factors identified in past studies can be further categorized into factors that defines the structure and functioning of organization--mainly individual factors (e.g., employee's passion and interest) and organizational factors (e.g., culture, climate, policies).

This study employed Scott, (2013)'s Institutional Theory as the theoretical lens to better understand the factors (both individual and organizational) that explain the grounds for employee retention. Paul J. Dimaggio, (1983) notion that institutional pressure promotes institutional isomorphism or homogeneity of organization, the reality indicates that not all organisations react to institutional pressure in a similar manner as cited in Jonge, (2015). Furthermore, "Investigations have moved away from a "one size fits all" view of turnover, favoring instead theories specifying the conditions under which particular factors are more or less important to quit decisions (or turnover rates) in a given setting Hom et al., (2017, p.539). In fact, researchers emphasise the necessity of analysing contextual boundary conditions of antecedent-turnover linkages e.g., Nyberg \& Ployhart, (2013). As there remains a dearth of studies that explored the factors that influence employee turnover and retention in the RMN, this study will use the conceptual framework proposed by Jonge (2015) as depicted in Figure 1 to analyse the underlying reasons for turnover among competent military divers in RMN [14] [22] [23] [24] [53].

We posit that competent military divers' decision to remain with the organisation or leave is influenced by four different forces. These forces include (1) Individual factor (the employees - the military divers), (2) Organisational Environment (the RMN practices), (3) Institutional Regulatory Environment (the RMN's HRM command control and legal system), (4) Social Environment and Culture Environment (the RMN's culture and custom, the peer and supervisor relationship with the military expert). These forces are interrelated and not mutually exclusive [23].

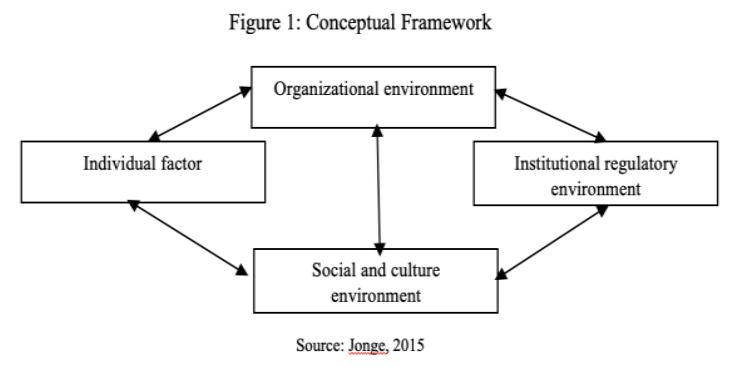

\subsubsection{Individual factor}

Individual element refers to an employee's intrinsic motivation. Intrinsic motivation includes a sense of purpose, demanding job, career progression opportunities, freedom to choose, and acknowledgment. Individuals benefit from intrinsic motives as a result of a sense of commitment. They will be intrinsically inspired by the task and its difficulties to find a solution by devoting their time and attention to investigating problems and devising creative solutions. They will be influenced to engage in whatever they are doing in order to meet their pleasure demands. A task's pleasure, interest, and readiness to explore fresh alternative strategies to get things done will draw the individual's attention. The employee will be able to make informed decisions about how to carry out the assigned tasks as an authority on the task. As a result, the employee will be naturally motivated to give novel and creative ideas while doing their job.

Individual intrinsic values, according to Dysvik and Kuvaas (2010), have a significant impact on employee turnover. The sense of success, praise, gaining a range of experience, and the autonomy to decide are thought to be the most significant predictors of employee retention from work itself. A happy, motivated, and committed individual will be the deciding element in whether or not an employee stays with the company [26]. In other words, a pleasant attitude at work will encourage employees to stay longer at the company [5] [15] [25] [27] [49].

\subsubsection{Organisational environment}

Organizational environment is used in this study to refer to organisational practises that may influence employees' decisions to stay with the company. Extrinsic motivational behaviours are among these factors. Extrinsic motivation, in contrast to intrinsic motivation, encourages employees to engage in a behaviour in order to receive rewards such as pay raises, recognition, promotion, perks, supervision, and company policies on sick leave and paid vacation [26] [28]. Employees can also be extrinsically driven on the job to attain some desired results such as receiving an award, avoiding guiltiness, avoiding a threatened punishment, or acquiring appreciation [29].

Individuals' decisions to stay in the firm are influenced by extrinsic factors. For example, the organization's training and development will foster a pleasant working environment conducive to a culture of continual learning. Because the workforce is quick to learn, they will progress at a constant rate and acquire skills quickly. Employee retention will benefit significantly from this extrinsic motive [9] [30]. Workplace flexibility is another example of extrinsic 
incentive. Flexibility in working hours and work arrangements are highly valued by the workforce. This enables them to arrange their schedule and create a timetable for completing the chores. Furthermore, workplace acknowledgment has an impact on the employee's trustworthiness and promotes development and progression [9]. Fundamentally, extrinsic motivation is supposed to encourage employees to stay with the company longer through improving morale [28]. While a reward system may improve performance and productivity, job happiness may suffer as a result [26] [28].

\subsubsection{Institutional regulatory environment}

The institutional regulatory environment refers to the Human Resource Management (HRM) policies that governs the HRM practices within the organization. Shah, Mallah, and Shabana (2015) and Wijesiri et al (2019) have studied HRM practices and how it affects employee retention. Shah et al., (2015) emphasised that HR practice should focus on recruitment and hiring, training and development, compensation and benefits, and evaluation and supervision. In his study, these were reported to have a prominent influence on employee retention [31] [32].

Wijesiri's et al., (2019) study is aligned with Shah et al's (2015) study to some level. He believes that, in addition to $\mathrm{HR}$ procedures such as recruiting the proper individual for the job, the organisation needs to build a strategic structure in which the entire team can contribute. The organisation should comprise of a workable and acceptable work process that is acknowledged by the workforce by allowing involvement in the company decision-making process to feel appreciated [31] [32].

Both authors have similar perspectives on how HR procedures affect employee retention. Additional parts of HR practises should include organisational fit and culture, family support, rewards, recognition, training and development, and career growth, as well as, most importantly, a pleasant workplace environment.

\subsubsection{Social environment and cultural forces}

The term "social environment and culture" in this study refers to the culture of the organisation as well as the connection between peers and supervisors. One aspect that has been found as an antecedent of employee retention is organisational and cultural values [33]. Human resources in the organisation will generate a positive environment through social or cultural engagement.

Relationships between peers and supervisors are part of a non-physical environment in which work-related relationships develop, both with managers and coworkers, as well as with subordinates [34]. This covers the manner in which leaders and subordinates interact. Fundamentally, upper management should communicate with employees to form a positive relationship as a supporting supervisor or coworkers by creating a positive and present work atmosphere. It has the potential to improve staff retention [7] [35] [[36] [37] [50] [51].

Furthermore, the leader's character and behaviour will boost retention, such as caring, being firm in decisionmaking, providing guidance and advice, and being a good motivator. Disrespect for employees, dishonesty, individualism, non-team player, and a large ego in the leader will result in a negative relationship between manager and subordinate, which will lead to turnover [7] [35] [36] [38] [50] [52].

In a nutshell, teamwork, security, and respect among employees are examples of social environment and cultural aspects. This improves employee loyalty and fosters long-term ties between the organisation and its personnel [7] [12] [33] [34] [36].

\section{METHODOLOGY}

\subsection{Research design}

This research will be applying the case study research method to identify factors that influence competent military divers' intention to stay. The qualitative research method by case study is primarily used to investigate, observe and understand the social phenomenon on the psychology and perception of the subordinate and superior level issues on the retention of employees in the organisation [39]. The use of the case study method will create the space and room to study the situation that is not having a clear set of outcomes from the start of the study. As pointed out by Yin (2011), we could use a descriptive case study framework to explore the phenomena by conducting interviews and subsequently reviewing the factors that affect an individual's turnover intention in the organisation and strengthening employee retention [39] [40].

The human attitude, value system, actions, motives, concerns, lifestyles, culture, and aspirations may all be better analysed and studied using qualitative methodologies. For the examination of employee retention, a case study in the qualitative method is the best fit. The primary goal of the case study is for the researcher to gain a comprehensive grasp of the scenario. The researcher will have direct involvement and acquire grade one data on many aspects affecting employee retention [30].

The researcher is fully aware that the qualitative case study method's research needs to consider the application of processual analysis in the study as pointed out by Prof Andrew Pettigrew with his favour 
Tay \& Sharmila/ International Journal of Business and Management, 5 (2) 2021, Pages: 06-16

tagline: 'Catching reality in flight' [47]. The processual analysis is to identify the inner and outer context of the study which concerned the why and when of change (the behaviour of the military divers in the RMN). The content which concerned the what of change (the RMN's HRM policies and practices). The process that concerned the how of change (the general public's engagement to be enrolled into the RMN as military personal) [47] [48]. The study will be within the time frame from the individual joining the RMN organisation until the end of their Retired-on Date (ROD).

\subsection{Unit of Analysis}

The study will use the purposeful sampling method to carry out the selection of the sample. This approach is made by selecting a sample of participants who meet the study's purpose. The populations for this study will be the competent military divers currently serving in the organisation and who has served to their compulsory retirement. These are the target group that the researcher needs to approach to understand their individual life experience and attitude to look for patterns and themes and determine their retirement reasons [41] [42].

Personnel who have submitted an official request to their Diving Unit management team indicating their commitment to serve until their required retirement date were chosen as samples. A total of 63 individuals were identified after getting the name list from HR Department on September 14, 2020. Their retirement on date (ROD) ranges from July 30, 2021, to July 19, 2024. A total of seven samples were identified from the list, all of whom had served for 18 years and were about to enter their 21st year, and whose ROD was between July 30 and January 2022. These 7 persons were identified as having ROD between July 30, 2021 and January 20, 2022, which is closer to the time of the research and allows for data collection in a reasonable amount of time. The ROD for the remaining 56 samples is from May 27, 2021 to July 19, 2024. Before the ROD, these 56 individuals may be subjected to a variety of unforeseeable conditions such as accidents, injury, health, medical status, and family work-life difficulties. All of the aforementioned unforeseeable circumstances may have an impact on their decision to retire.

Before beginning the interview, the participants will be briefed and asked to sign a consent form. The necessary precautions will be taken to ensure that the participants' personal information remains private. It entails labelling the information gathered from interviewees as nominal and putting it in a secure folder.

\subsection{Data Collection}

The participants in the study were asked to sign a consent form to affirm their willingness to participate. They were briefed in advance on the study's goal as well as the definitions of key terms like turnover. Before beginning the actual interview, the sample will be given the opportunity to discuss their concerns with the researcher.

The researcher and sample's interview conversation were audio recorded for data analysis purposes. The interview was recorded and then imported into a qualitative data analysis programme for coding in order to produce the needed themes for study. As data was collected, a qualitative research spreadsheet log was established and updated [43]. Following the interview, the next step is to formulate the population's collective response. The data is then analysed in preparation for report authoring [40]. The researcher was alert and cautious throughout the data collecting and analysis procedure to prevent bias and assure the validity and reliability of data while conducting interviews and drafting the report. One-sided information interpretation, selection of specific theme prejudice, and finally not having predetermined preconceptions are among the various biases that the researcher closely examined.

\subsection{Data Analysis}

The information gathered was organised in a methodical manner for data coding and interpretation. This information helps the researcher to examine and analyse the data to find themes and trends in employee turnover and retention. The coded documents were analysed using Qualitative Data Analysis computerassisted software to identify the themes and patterns. The software was used as a tool to manage, analyse and shape the qualitative data. Keywords and phrases were used to code the available data to identify the similarities and themes. An audit trail was kept of the audio recording from the interview session. The study's process was followed from the beginning of data collecting to the end of data analysis and presentation [40] [43].

\subsection{Reliability}

The study must meet the trustworthiness criteria, which include conducting the interview in a comprehensive, meticulous, and honest manner. This criterion ensures that the research is reliable and may be incorporated into the body of knowledge for future use. When approaching the research, the researcher consciously used the method of bracketing himself to avoid prejudice and preconceived notions in order to assure its validity and reliability [43] [44]. 
During the interview, the researcher produced an environment in which the samples felt at ease and formed a good rapport. As a result, the samples felt more at comfortable with the researcher and were more eager to disclose their real-life experiences related to the study issue. As a result of its consistency and dependability, the data is regarded as of high quality. The interview protocol was audio-recorded and kept for audit trial to promote consistency [39] [40] [43] [44] [45].

\subsection{Validity}

The research's validity is determined by three primary factors. The researcher's prejudices are discussed in the first segment. The researcher was well aware of the necessity to keep himself from influencing the sample that would be interviewed. He was also well conscious of his potential for bias as a result of his knowledge and assumptions about research and the research strategy's sample selection and research design procedure.

The second segment is about the researcher's reactivity. He was aware of the possible influence on the research situation or setting, including the sample that is within the boundary. While collecting data, the researcher once again bracketed himself with trustworthiness, honesty, and alertness.

The respondent's bias is discussed in the final segment. The researcher is aware that when asked to provide honest responses during the interview, the sample may or may not cooperate with the researcher. The researcher has established a rapport with the sample in order for the data obtained to be reliable and of high quality for the study's benefit [40] [44].

The researcher used numerous other tactics to improve reliability and validity in order to achieve reliability and validity. This includes: Having a prolonged involvement in engagement with the identification of the purposeful sample to collect the data; Carry out member checking with the participants as required to double-check the results of the data analysis; Create a proper record of the data collection and analysis to derive findings for audit trails. These tactics are intended to improve the reliability and validity of qualitative research [39] [40] [43] [44]. Fundamentally, the researcher must be careful while probing the phenomenon of the study with practical questions so that participants can provide relevant facts without overinterpreting [46].

\section{RESULT ANALYSES AND DISCUSSIONS}

\subsection{Factors influencing the retention of competent military divers}

The study results obtained were categorised into relevant themes and subthemes guided by the
Institutional Theory. The preliminary objectives of the study are to identify factors that influence early turnover and how these factors can be better addressed to retain these military divers. The factors are presented in Table 1 below.

Table 1: Factors That Influencing the Early Turnover and Retention of Military Divers in the RMN

\begin{tabular}{|c|c|c|c|}
\hline Theme & Subtheme & File & $\begin{array}{c}\text { Coded } \\
\text { reference }\end{array}$ \\
\hline \multirow{6}{*}{ Individual } & Commitment & 7 & 200 \\
\hline & $\begin{array}{l}\text { Employee } \\
\text { engagement }\end{array}$ & 7 & 139 \\
\hline & Job satisfaction & 7 & 104 \\
\hline & Shocks & 7 & 103 \\
\hline & Job security & 5 & 26 \\
\hline & Job stress & 3 & 22 \\
\hline \multirow[t]{2}{*}{$\begin{array}{l}\text { Organization } \\
\text { environment }\end{array}$} & $\begin{array}{l}\text { Work-life } \\
\text { balance }\end{array}$ & 7 & 133 \\
\hline & $\begin{array}{l}\text { Organizational } \\
\text { justice }\end{array}$ & 7 & 41 \\
\hline $\begin{array}{l}\text { Social } \\
\text { environment }\end{array}$ & $\begin{array}{l}\text { Organizational } \\
\text { support }\end{array}$ & 5 & 15 \\
\hline \multirow{7}{*}{$\begin{array}{l}\text { Institutional } \\
\text { regulatory } \\
\text { environment }\end{array}$} & $\begin{array}{l}\text { Training and } \\
\text { development }\end{array}$ & 7 & 162 \\
\hline & Benefits & 7 & 97 \\
\hline & $\begin{array}{l}\text { Career } \\
\text { management and } \\
\text { growth }\end{array}$ & 7 & 65 \\
\hline & $\begin{array}{l}\text { Compensation } \\
\text { and reward } \\
\text { system }\end{array}$ & 6 & 50 \\
\hline & $\begin{array}{l}\text { Performance } \\
\text { appraisal }\end{array}$ & 5 & 17 \\
\hline & Health and safety & 2 & 8 \\
\hline & $\begin{array}{l}\text { Flexible work } \\
\text { arrangement }\end{array}$ & 3 & 5 \\
\hline
\end{tabular}

The factors that can influence the retention of military divers and prevent early turnover were the focus of the findings reported here. Diver's decision-making on whether to stay of leave RMN was found to be influenced by a variety of circumstances, both positive and negative. The HR department and Diving Team management will use the factors listed in Table 1 to develop a strategic retention plan to entice military divers to serve until their ROD.

Evidently, individual variables appear to play a significant effect in the retention of skilled military divers. Divers were motivated to stay loyal to the organisation when they had the correct mindset, which included commitment to their profession, involvement, and satisfaction. As long as the divers remained passionate, they were willing to remain with RMN. The following quote lends support to this notion.

Sample 1: "One of the reasons for joining the uniform body is because of the interest I had. I came because of interested in it. Even though we need to work hard, we are happy because of our 
interests. Although we are tired, we are happy. We want to learn a lot more. As we go further, we want to know more about diving, so we keep moving forward. I am one of those involved in the Australian Diving Accreditation Scheme (ADAS). When we have the ADAS, I feel like a loss if I don't share. So, I share with others. After all, I am in the Training department. When there is an opportunity for me to share the knowledge, I will do it"

On the contrary, when they experience adversities such as shocks and stress, they are prone to consider the possibility to leave the organization. For instance, the norms at KD PELANDOK where the competent divers are stationed contradicted with the norms the divers were used to as noted in the following quote.

Sample 7: "They are many of them come from PULARAK, after report to KD PELANDOK they are absentees, this is because they are surprised and shock on the two different routines. Feel like being lockdown and many restrictions to comply. The difference atmosphere between PULARAK with KD PELANDOK. At PULARAK, they will eat in line in the mess, and there were duty staff to serve them. When they report at KD PELANDOK, they have to be independent, and when they came in late or whatever happens, he will feel depressed."

In terms of organizational environment, these divers emphasized the need for an environment that promotes work-life balance. When a regular civilian joins the RMN as a sailor, their lifestyle and culture are completely transformed. They will be exposed to completely new and strict laws and regulations that they must follow as military members. The military will work 24 hours a day, seven days a week, as opposed to a civilian who works an 8-to-5 shift. Sailors may be required to work over the clock, or those serving onboard may be required to leave their families behind for a protracted voyage at sea or on an oversea mission. This long travel may cause stress and disrupt the sailor's and family member's work-life balance. As a result, these capable divers stressed the need of promoting work-life balance as a reason to stay loyal to RMN.

Furthermore, the experienced divers emphasised the importance of maintaining a fair environment. They acknowledged that RMN is a military organisation, and that everyone is bound by military rules and regulations, as laid out in the Armed Forces Act 1972 (AF Act 72). Albeit the strict environment, they appreciated the fact that an accused individual will be given a fair trial based on the charges or complaints levelled against him. Before a decision is reached, a thorough board of inquiry or investigation will be performed to determine the authenticity of the charges or complaints. Only when a sailor is found guilty will he be penalised in accordance with AF Act 72. The participants expressed gratitude for the fair system within RMN that allows them to forward their complaints and voice their dissatisfaction to higher management via the Commanding Officer complaints table, which is then passed up to the Admiral Table and, if necessary, to the Chief of Navy Table. This procedure assures that the sailor is treated fairly and honestly in order to avoid a cover-up.

Next, organisational support was mentioned as one factor that could better explain the social environment expected in the RMN. The participants emphasised the importance of management's organisational support in their decision to leave the unit and quit early. After long and strenuous working hours, especially after a long sea deployment, divers, for example, require time off to care for ill and weak family members, domestic housekeeping needs, and family quality time. Day offs are necessary for the employee to re-energize and prepare for the next long deployment away from home and family.

Furthermore, the participants appreciated the effort by RMN to provide support to their family especially when they are away on duty. The RMN Wife Welfare Group which is led by the unit commanding officer's wife named Badan Kebajikan Keluarga Angkatan Tentera Laut (BAKAT Laut) is one such example. When their husbands are gone serving the country at sea, BAKAT Laut will be able to provide basic feminine support to their wives and children. The organisation is able to provide personnel, transportation, and minimal financial assistance to sailor's family members who are in need, particularly when the husband is gone. If a sailor or family member need particular medical attention, the organisation can make arrangements with the nearest military or government hospital. If a sailor needs to be closer to a family member due to a welfare reason (aging parents or a wife unable to transfer closer to her husband's workplace), the organisation can arrange for him to be transferred to the nearest naval base to shorten the travel time and reduce the financial burden on the family. These are some of the organisational support services that are under the jurisdiction of the RMN policies and practises. The sailor's hearts and minds will be won over by this organisational support, which will inspire them to continue serving.

Finally, Institutional regulatory environment encompassed HRM policies. Among the policies frequently talked about included training and development, benefits, career management and growth, compensation, and reward system. These policies were mentioned numerous times implying the importance of these policies. The participants highlighted growth opportunities, training and 
development, career growth, and benefits as factors that served as a pull factor for them to remain with RMN. There are many benefits that have been put in place to attract the sailor to join the RMN and continue to serve the organisation. Besides getting their monetary compensation in terms of pay and deserved allowances such as service allowance and housing allowance. There are also able to entitle to temporary duty claim, annual leave claim, home to duty claim, free meals provided when they are on duty or sailing onboard ship, free uniform from head to toe and many more. Low-interest government housing loan is another attractive pull factor for the sailor to remain in the organisation. For those that who do not own a house, they are provided with basic furnished government quarters which is especially suitable for the newlywed couple who just started their family life. Furthermore, for those that have served their 21 years, retirees will be entitled to a full pension. They can use their military diving skills and HR management skills which they obtained during their tour of duty in the organisation to pursue their 2 nd career after retiring. They are only about 40 years of average age after retirement and still marketable in the corporate world.

In terms of compensation, the organisation has revised the pay scheme of Band 5 for all branches since 2016. This shift has resulted in a salary difference between branches. The management team must accept that one of the major reasons for the sailors' demoralisation is the disparity between their hard work and reward. This unfair pay grade deters sailors from joining the branch, and the organisation must alter it. The diving allowed is still another deterrent. Before the understaffed situation in the organisation worsens owing to individual early departure, the organisation needs to reassess its policies to raise the pull factor on compensation. Another method is to use non-monetary incentives such as service recognition, promotion, and attendance at local and international courses to boost the individual's pull factors. The participants suggested that RMN reviews the pay grade to differentiate from other branches in the RMN and increase the diving allowance as one of the pull factors to attract new divers to join the branch.

\subsection{Recommendations}

This study suggests numerous recommendations that RMN might apply to increase competent military diver retention based on the characteristics indicated above and comments collected from the participants.

Firstly, RMN should be aware that intrinsic motivation will eventually drive the individual's decision to remain loyal to the organization. Recruits should be passionate about their choice to work as a military diver and should be resilient towards the challenging nature of the job. Fundamentally, they should be attached to the organisation because they want to and not because they need to. Hence, passion and resilience of the recruits should be included as one of the primary criteria in the recruitment exercise. When recruits sign up voluntarily, they will not view the job as a hassle/shock and is committed to remain loyal to RMN.

Next, RMN should focus on catering to individual extrinsic needs and satisfying them in order to promote commitment and engagement among them. RMN should provide a trusted organizational environment so that the workforce can feel like they have been treated fairly and equally. Human resource wellbeing should be taken care of so that they feel valued and dedicated to continuing to serve the organisation. The HRM team at the company level must be able to establish a good working environment that is appropriate for and accepted by all levels of the workforce.

Third, constant monitoring and improvement of HRM policies are required by the organisation to deal with the changes and new challenges. RMN should adopt a proactive approach and seek input from the employees to understand their grievances. For instance, the challenging nature of the job of a military diver should be considered when deciding on the special allowance. Adopting a blanket rate regardless of the nature of the job will induce feeling of dissatisfaction and drive the competent divers to seek other opportunities. Hence, equity should be given due consideration when making important decisions related to HRM policies.

Finally, the best practices should be sustained to ensure these practices remain as a pull factor in retaining competent divers. While there are lucrative paying job opportunities in the private sector, those opportunities are not able to provide the security and growth opportunities that comes with RMN benefits programs. Albeit the lower pay, the plus points of RMN's benefits should be capitalized upon to ensure the divers are motivated to remain with RMN.

In a nutshell, a proactive approach should be adopted by RMN to ensure the organisation are able to mitigate the phenomenon of an early turnover and able to retain the workforces until their compulsory retirement. While the rules and regulations in the organisation must be enforced and implemented, opportunities should be made avail for divers to voice their needs and grievances. Only then will RMN be able to understand the gaps and address issues that are driving their competent divers to retire before time. Doing so will help address the shortage of divers and ensure that the organisation has a highly motivated and disciplined workforce to perform their duty and serve the country. 
Tay \& Sharmila/ International Journal of Business and Management, 5 (2) 2021, Pages: 06-16

\section{CONCLUSIONS}

Military divers are the only elite unit in the MAF with specialised training to support military operations, including diving and mine removal. To guarantee that military divers are always prepared to perform their roles and tasks, the RMN HR department must develop an appealing retention strategy plan to keep these highly qualified individuals in the organisation.

The findings suggest that both individual factors and organisational factors such as HRM policies have a pertinent impact on the retention of military divers. Extrinsic and intrinsic motivation will impose great pressure on the individual decision on whether to serve until their compulsory retirement. The organisation needs to take positive measures on the crafted HRM policies and practices seriously so that their workforce will remain passionate about their job and are willing to serve until their compulsory retirement. This will facilitate the process of mitigating early turnover in the organisation and ensure RMN is able to retain the skilled divers who will continue to support the naval operation as required by the organisation.

Whatever strategy we devise, we must ensure that it is relevant to the workforce, given their evolving goals and social interaction requirements. We need to learn more about employee retention and individual needs, as well as how they interact inside an organisation. To keep our workforces [31] [32], we need to have both inner and extrinsic motives that are sustainable.

\section{REFERENCES}

[1] DMW, C. (1994). Dasar Penyelam TLDM, RMN Navy HQ.

[2] RMN Diving and Mine Warfare, C. (2013). Standard Operation Procedure for RMN Diving and Mine Warfare RMN Diving and Mine Warfare HQ.

[3] Kaur, R. (2017). Employee retention models and factors affecting employees retention in IT companies. International Journal of Business Administration and Management, 7(1), 161-174.

[4] Division, R. I.A. R. (2019). RAND Corporation, Non-profit Research Centre.

[5] Azeez, S. A. (2017). Human resource management practices and employee retention: A review of literature. Journal of Economics, Management and Trade, 1-10.

[6] Farinacci, R. R. (2012). Developing retention strategies concerning first-term airman: A qualitative method study with a case study research design on First-Term Airman at Luke Air Force Base. University of Phoenix.

[7] Das, B. L., \& Baruah, M. (2013). Employee retention: A review of literature. Journal of business and management, 14(2), 8-16.
[8] Richman, A. L., Civian, J. T., Shannon, L. L., Jeffrey Hill, E., \& Brennan, R. T. (2008). The relationship of perceived flexibility, supportive work-life policies, and use of formal flexible arrangements and occasional flexibility to employee engagement and expected retention. Community, work and family, 11(2), 183-197.

[9] Hee, O. C., \& Rhung, L. X. (2019). Motivation and employee retention among millennials in Malaysia. International Journal of Academic Research in Business and Social Sciences, 9(2), 876-884.

[10] Bankar, S., Kakade, M. D., \& More, M. A. (2016). Employee Turnover-A Study of its Cause and Effect with Special reference to Automobile Sector. International Journal of Advanced Engineering Research and Science (JJAERS), 3(2), 11-14.

[11] Lu, L., Lu, A. C. C., Gursoy, D., \& Neale, N. R. (2016). Work engagement, job satisfaction, and turnover intentions: A comparison between supervisors and line-level employees. International Journal of Contemporary Hospitality Management, 28(4), 737-761.

[12] Ngo-Henha, P. E. (2018). A review of existing turnover intention theories. International Journal of Economics and Management Engineering, 11(11), 2760-2767.

[13] Van Dick, R., Christ, O., Stellmacher, J., Wagner, U., Ahlswede, O., Grubba, C., ... \& Tissington, P. A. (2004). Should I stay or should I go? Explaining turnover intentions with organizational identification and job satisfaction. British Journal of Management, 15(4), 351-360.

[14] Hom, P. W., Lee, T. W., Shaw, J. D., \& Hausknecht, J. P. (2017). One hundred years of employee turnover theory and research. Journal of Applied Psychology, 102(3), 530-545.

[15] Lee, L., \& Chen, L. F. (2018). Boosting employee retention through CSR: A configurational analysis. Corporate Social Responsibility and Environmental Management, 25(5), 948-960.

[16] Johnson, S., \& Pike, B. (2018). Employee Retention: The State of Engagement in Public Accounting Firms and Why It Matters. The CPA Journal, 88(12), 64-66.

[17] Lee, T. W., Hom, P., Eberly, M., \& Li, J. (2018). Managing employee retention and turnover with 21st century ideas. Organizational dynamics, 47(2), 88-98.

[18] Younge, K. A., \& Marx, M. (2016). The value of employee retention: Evidence from a natural experiment. Journal of Economics \& Management Strategy, 25(3), 652-677.

[19] Kwon, K. A., Malek, A., Horm, D., \& Castle, S. (2020). Turnover and retention of infant-toddler teachers: Reasons, consequences, and implications 
for practice and policy. Children and Youth Services Review, 115, 105061.

[20] Scott, J., Waite, S., \& Reede, D. (2020). Voluntary Employee Turnover: A Literature Review and Evidence-Based, User-Centered Strategies to Improve Retention. Journal of the American College of Radiology, 18(3), 442-450.

[21] Yang, J. T., Wan, C. S., \& Fu, Y. J. (2012). Qualitative examination of employee turnover and retention strategies in international tourist hotels in Taiwan. International Journal of Hospitality Management, 31(3), 837-848.

[22] Scott, W. R. (2013). Institutions And Organizations: Ideas, Interests, and Identities (4th Edition ed.). USA: SAGE Publications.

[23] De Jonge, A. (2015). The glass ceiling in Chinese and Indian boardrooms: Women directors in listed firms in China and India. Elsevier.

[24] Nyberg, A. J., \& Ployhart, R. E. (2013). Contextemergent turnover (CET) theory: A theory of collective turnover. Academy of Management Review, 38(1), 109-131.

[25] Dysvik, A., \& Kuvaas, B. (2010). Exploring the relative and combined influence of masteryapproach goals and work intrinsic motivation on employee turnover intention. Personnel review, 39(5), 622-638.

[26] Mgedezi, S., Toga, R., \& Mjoli, T. (2014). Intrinsic motivation and job involvement on employee retention: Case study-A selection of eastern cape government departments. Mediterranean Journal of Social Sciences, 5(20), 2119-2119.

[27] Mandhanya, Y. (2015). A Study Of Impact Of Working Environment On Retention Of Employees (With special reference to Automobile sector). Global Management Review, 9(4), 116128.

[28] Edrak, B. B., Yin-Fah, B. C., Gharleghi, B., \& Seng, T. K. (2013). The effectiveness of intrinsic and extrinsic motivations: A study of Malaysian Amway Company's direct sales forces. International Journal of Business and Social Science, 4(9), 96-103.

[29] Dysvik, A., \& Kuvaas, B. (2013). Intrinsic and extrinsic motivation as predictors of work effort: The moderating role of achievement goals. British Journal of Social Psychology, 52(3), 412-430.

[30] Mishra, S., \& Mishra, S. (2017). Impact of intrinsic motivational factors on employee retention among Gen Y: A qualitative perspective. Parikalpana: KIIT Journal of Management, 13(1), 31-42.

[31] Shah, M. A., Mallah, M., \& Shabana, M. (2015). Impact of Human Resources Practices on Employee Retention: Study of Community Colleges. Case Studies Journal, 4 (8).

[32] Wijesiri, N. S., Paranagama, G. S., Sirirwardhana, M. M., Thilakarathna, D. L. N. C., Weerarathna, R. S., \& Pathirana, U. P. G. Y. (2019). The Impact of
HR Practices on Employee Retention; A Case of BPO Sector, Sri Lanka. International Journal of Human Resource Studies, 9(1), 1-21.

[33] Rustam, H. (2020). Talent Management: Improvement of the Employee Selection and Retention Process through Service Design: Development of The Employee Journey Map to impact employee retention.

[34] Sadikin, M. R., Junaedi, J., \& Prianti, A. R. (2020, February). What Company Can Learn From Employee Turnover Intention. In 4th International Conference on Management, Economics and Business (ICMEB 2019) (pp. 1-5). Atlantis Press.

[35] Demirtas, O., \& Akdogan, A. A. (2015). The effect of ethical leadership behavior on ethical climate, turnover intention, and affective commitment. Journal of Business Ethics, 130(1), 59-67.

[36] Arokiasamy, A. R. A. (2013). A qualitative study on causes and effects of employee turnover in the private sector in Malaysia. Middle-East Journal of Scientific Research, 16(11), 1532-1541.

[37] Faltas, M. (2021). Devising Communication strategies for Retaining Employees.

[38] Oke, A. O., Ajagbe, M. A., Ogbari, M. E., \& Adeyeye, J. O. (2016). Teacher retention and attrition: A review of the literature. Mediterranean Journal of Social Sciences, 7(2 S1), 371.

[39] Myers, M. D. (2013). Qualitative Research in Business and Management (K. Smy Ed. 2nd Edition ed.). Washington DC: SAGE Publications.

[40] Yin, R. K. (2011). Qualitative Research From Start To Finish. (C) 2011 The Guilford Press.

[41] Creswell, J. W. (2009). Research Design Qualitative, Quantitative, and Mixed Methods Approaches. SAGE Thousand Oaks, CA: SAGE Publications.

[42] Patton, M. Q. (2002). Qualitative Research and Evaluation Methods. SAGE Publications, Thousand Oaks, CA: SAGE.

[43] Miles, M. B., Huberman, A. M., \& Saldana, J. (2014). Qualitative Data Analysis, A Methods Sourcebook (H. Salmon Ed.). USA: SAGE Publications, Inc.

[44] Abdullah, H. (2019). Research Methods and Report Writing National Defence University of Malaysia (UPNM): UPNM Press.

[45] Neuman, W. L. (2014). Social Research Methods: Qualitative and Quantitative Approaches. Pearson Education Limited: Pearson.

[46] Sinkovics, R. R., Penz, E., \& Ghauri, P. N. (2008). Enhancing the trustworthiness of qualitative research in international business. Management International Review, 48(6), 689-714.

[47] Pettigrew, A. M. (1997). What Is A Processual Analysis? Scand.LMgmt, 13 (4), 337-348, pp.337348.

[48] Cheah, K. S. (2015). Processual analysis on organizational decision-making: A practical 
Tay \& Sharmila/ International Journal of Business and Management, 5 (2) 2021, Pages: 06-16

approach to explore teachers' decision-making and classroom management in a private secondary school in subang, selangor. Procedia-Social and Behavioral Sciences, 172, 709-716.

[49] Covella, G., McCarthy, V., Kaifi, B., \& Cocoran, D. (2017). Leadership's Role in Employee Retention. Business Management Dynamics, 7(5), 1-15.

[50] Munish, R. A., \& Agarwal, R. (2017). Employee engagement \& retention: A review of literature. International Journal of BRIC Business Research, 6(1), 1-19.

[51] Johari, J., Tan, F. Y., Adnan, Z., Yahya, K. K., \& Ahmad, M. N. (2012). Promoting employee intention to stay: do human resource management practices matter? International Journal of Economics and Management, 6(2), 396-416.

[52] Seirafi, N. (2020). Workforce Generational Differences, Leadership, and Employee Turnover: Focus on Millennials Retention. California State University-Northridge.

[53] Paul J. DiMaggio, W. W. P. (1983). The Iron Cage Revisited: Institutional Isomorphism and Collective Rationality in Organizational Fields. American Sociological Review, Vol. 48, No. 2 (Apr., 1983), pp. 147-160, 147-160. 